\title{
Failure to produce improvement in ECT documentation
}

\author{
Peter Childs and J. Guy Edwards
}

"Progress, far from consisting in change, depends on retentweness ... those who do not remember the past are doomed to repeat it" (George Santayana, 1863-1952).

A provious survey comied out in our unit revecied deficiencies in electroconvuletve thercipy (ECT) documentation. With the cim of correcting these deficiencies, the standard procedure for completing the aucilt cycle was followed and the survey was repected. The results question the casumption that simply completing the cuclit cycle 'cutomatically' loads to on improvement in practice. Poesible recisons why improvement did not como cbout in this study are cliscusised.

Most published reports on psychiatric audit have been based on surveys of current practice. Such surveys are important, but they are only points of entry into audit cycles; to demonstrate that audit has contributed to an improvement in clinical practice it is necessary to complete the cycle. It is assumed that if this is done improvement will automatically follow, but improvement does not necessarily occur.

We present here the results of audit of electroconvulsive therapy (ECT) documentation which, although carried out in a structured way. did not lead to improved practice. Possible reasons for this are discussed and proposals are made that could help facilitate monitoring.

\section{The study}

The study was one of a series of audit exercises in a well established programme (Edwards, 1991). All medical staff in our unit participate in this programme and during recent years university lecturers and senior registrars in psychiatry have been encouraged to take the lead in specific projects. One of us (PC) was a lecturer in psychiatry when our ECT study was carried out.

It was already known that the administration of ECT often fails to meet agreed standards (Pippard, 1992). A year before our study was carried out, a survey of ECT documentation in our unit carried out by a former senior registrar revealed a number of deficiencies (Delaney, 1992). The aim of the audit was to help correct these deficiencies. The results of the earlier study were therefore presented in one of our regular audit meetings and all psychiatrists were circulated with a written summary of the deficiencies previously identified. An attempt was then made to collect information on a structured data collection (sheet designed specifically for the purpose) on all patients who recetved ECT during the subsequent six months. These data should be routinely recorded by trainee psychiatrists on an ECT prescription form and in patients' case records. The type of information collected is shown in Tables 1 and 2. The information was extracted from all readily available case notes by 20 senior or junior doctors, each of whom reviewed the records of up to four patients during a two week survey period.

\section{Findings}

The records of 50 patients were assessed. Those of another 20 patients were not readily obtainable for various reasons (especially shortage of medical records staff) or were not adequately assessed by those helping in the audit. Data from the $\mathbf{5 0}$ subjects, together with the results of the earlier survey, are summarised in Tables 1 and 2.

\section{Comment}

For audit to succeed it has to be sensittve to staffing and other difficulties in the unit in which it is carried out, and the methodology has to be adapted to these difficulties. As a result, those carrying out audit have to tolerate greater imperfection than those undertaking research. In the present study, for example, we had to accept that a large number of case records were not readily available during the two-week period in which data were collected. This would have been unacceptable in research and could have introduced a bias in this study. However, the proportion of temporary missing records was similar to that in the previous audit and is therefore unlikely to have had a major influence on our results.

We found that agreeing on standards of practice, observing the extent to which they were 
Table 1. Patient characteristics

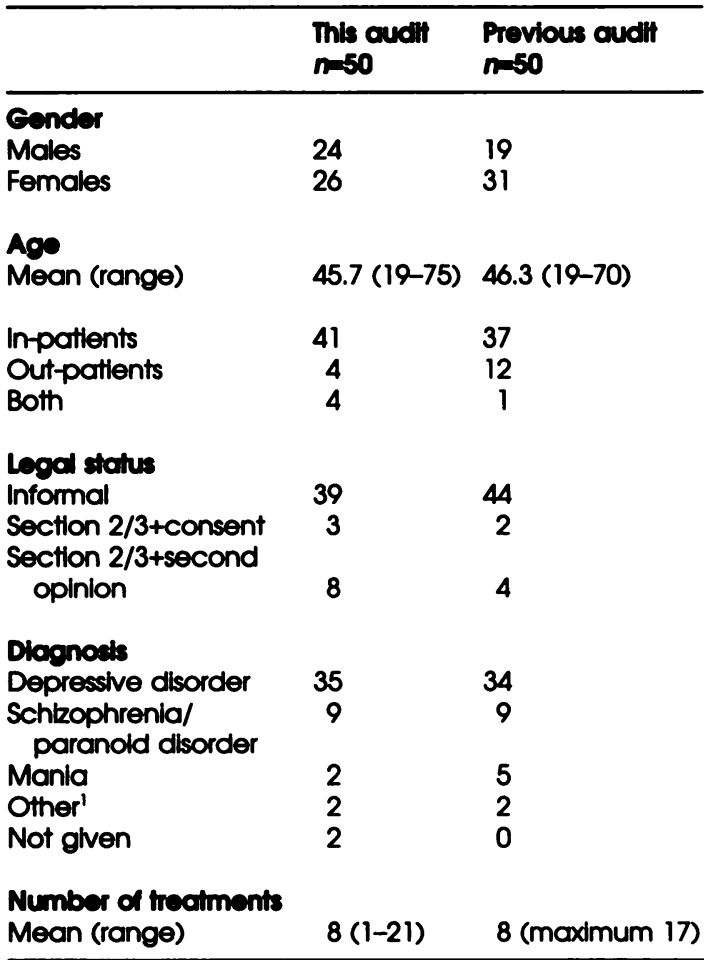

1. One depression following benzodiazepine withdrawal, one 'acute psychosis' - not otherwise specifled.

being met, pointing out deficiencies to colleagues and repeating the observations (i.e. completing the audit cycle) did not lead to the improvement expected. In some areas there was a decline in performance. Documented information on the reasons for initiating and stopping ECT and the physical examination were worse, although there was an improvement in the recording of the response to ECT.

There are a number of possible reasons for these disappointing results. It is concetvable that the importance of documentation (for both clinical and medico-legal reasons) and the previous audit findings were not emphasised as much as they should have been, although a more likely explanation is that, when working under pressure and dealing with more urgent clinical matters, documentation takes second place or is forgotten. A third possibility is that 'audit fatigue' sets in, especially in a unit such as ours where a series of audit exercises, each leading to recommendations for improving practice, makes ever increasing demands on trainees who already have a vast amount of new information to assimilate.

Whatever the case, better results could possibly come about by more efficient induction procedures for new trainees and more intense super-
Table 2. Audit documentation

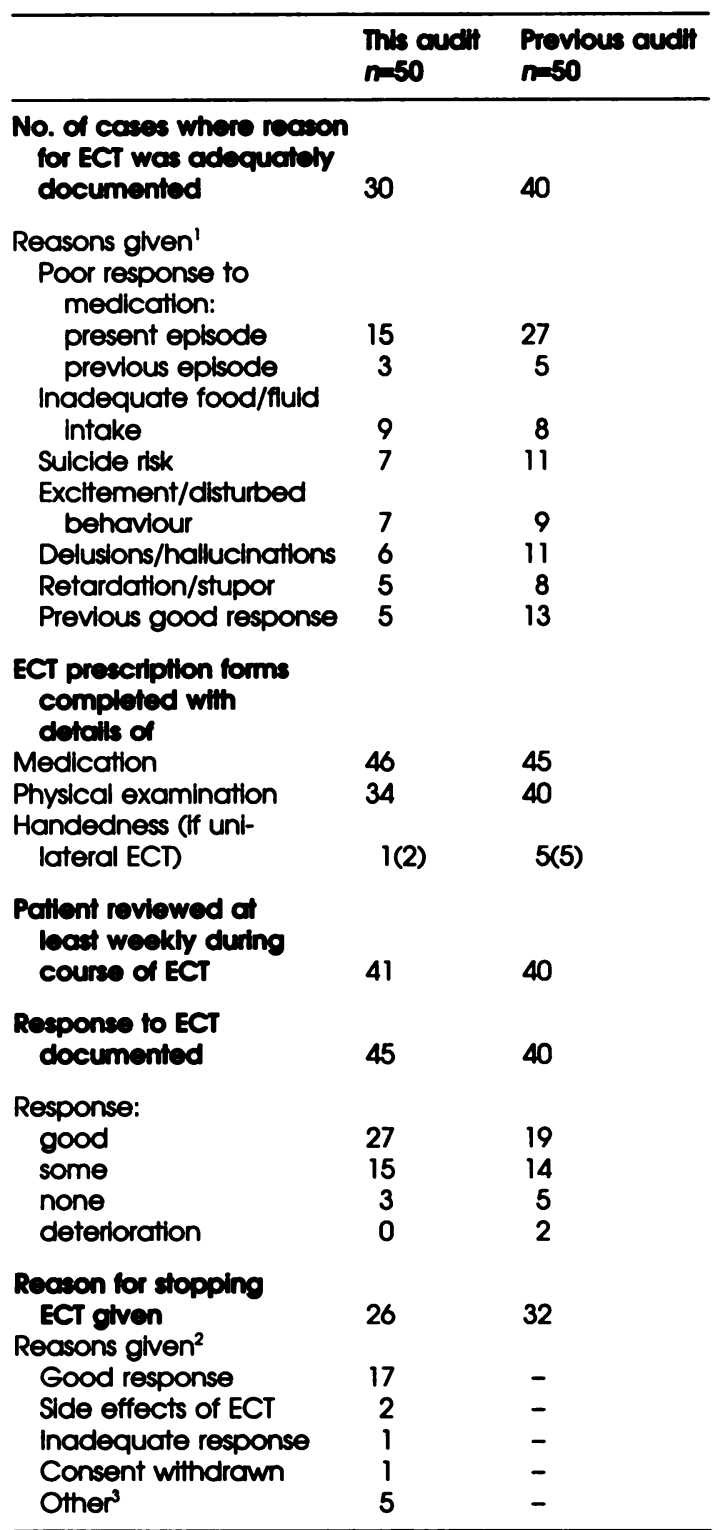

1. Total exceeds 30 because more than one reason given. 2. Data on this item not recorded in the previous audit. 3. 'Progress levelled off' (1), 'uncertain whether Improvement due to $\mathrm{ECT}^{\prime}$ (1), 'mania halted but patient becoming depressed' (1), patient discharged herself (1), and 'does not come across as morbidly depressed' (1).

vision by consultants or senior registrars, as recommended by the Royal College of Psychiatrists (1989, 1995). More complete documentation could also be ensured by the use of an unambiguously structured ECT record sheet. 
such as that suggested by the Royal College of Psychiatrists (1995). Part of the form could be completed by the trainee involved in the general care of the patient and a part completed by the doctor administering ECT. Such a form should be easy to complete (even by a trainee who has been up all the previous night admitting emergencies) and could provide an easy means by which medical managers can monitor the extent to which agreed procedures in ECT (or other treatment) are followed. In some areas a proforma could even bypass the need for more timeconsuming and expensive audit.

\section{Acknowledgements}

We thank Mrs Jean Currie and Mrs Lyn Benham for their help in locating and distributing medical records, our medical colleagues for extracted data for the audit, and Mrs Althea Edwards for secretarial help.

\section{References}

Delaney, N. (1992) Good practice in ECT. Psychlatilc Bullettn, 16, 272-273.

EDWARDS, J. G. (1991) A decade of psychlatric audit in Southampton. Psychiatric Bullettn, 16. 732-734.

PIPPARD, J. (1992) Audit of ECT in two National Health Service reglons. Brttsh Joumal of Psychlatry, 160. $621-637$.

RoYal Counge of PSYCHIATRISTs (1989) The Practical Administration of Electroconvulstue Therapy (ECT). London: Gaskell.

- (1995) The ECT Handbook. The Second Report of the Royal College of Psychiatrists' Special Committee on ECT. London: Royal College of Psychiatrists.

Peter Childs, Consultant Psychiatrist; and *J. Guy Edwards, Honorary Clinical Senior Lecturer, University Department of Psychiatry, Royal South Hants Hospital, Southampton SO14 OYG

-Correspondence

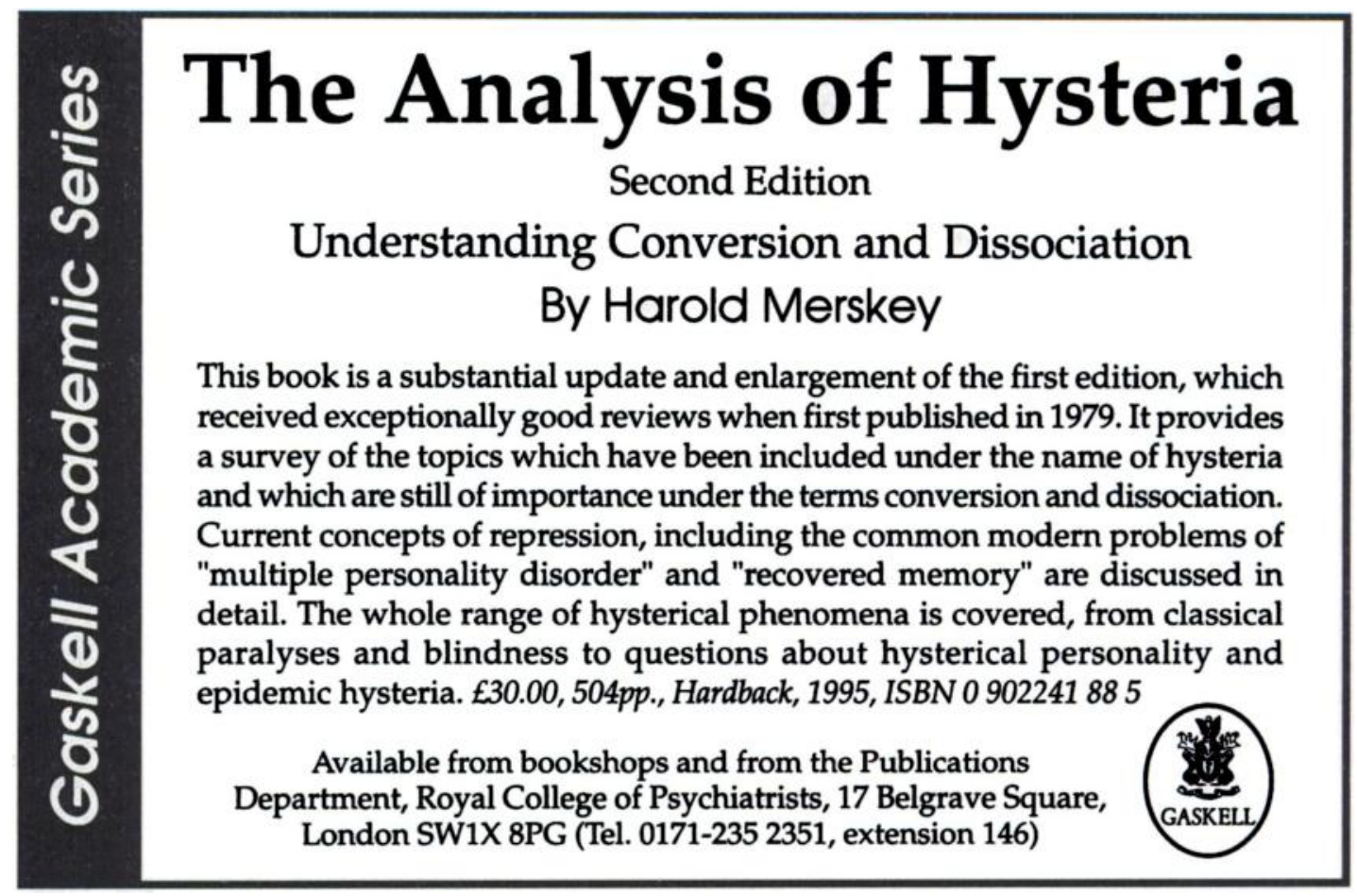

